\title{
Transferring results of behavioral research to industry to improve animal welfare on the farm, ranch and the slaughter plant ${ }^{2}$
}

\author{
Temple Grandin \\ Department of Animal Sciences, Colorado State University, Fort Collins, CO 80523-1171, USA
}

\begin{abstract}
Knowledge obtained from research has been effectively transferred to the agricultural industry in some areas and poorly transferred in others. Knowledge that has been used to create a product such as a pharmaceutical or a device is more likely to be adopted by industry than a behavioral management technique. During my career, I have observed that some people will purchase a new cattle-handling system, which is designed with animal behavioral principles, but they will continue to handle cattle roughly. People are more willing to purchase new equipment than they are to use easy-to-learn, lowstress handling techniques. Even when financial benefits are clear, some people find it difficult to believe that a behavioral management method really works.

From my experience, I have learned that successful transfer of knowledge and technology to industry often requires more work than doing the research. For an effective transfer of technology to take place, the method or equipment must be used successfully by the people who initially adopt it. If the new piece of equipment fails on the first or second place that attempts to adopt it, transfer to the industry may fail. In this paper, I describe a successful case study of transfer of a conveyor restrainer system, based on behavioral principles, from the research lab to US and Canadian beef slaughter plants. I also describe the successful implementation of a measurement system for auditing animal handling in slaughter plants. Based on my experience, the following steps for successful transfer of behavior research to the industry are: (1) Communicate your results outside the research community. Write articles in popular and industry magazines. Speak at producer meetings and develop websites that can be used to transfer research results into practice. (2) Choose places (e.g. farms or plants) that have managers who believe in your research, and be prepared to spend a lot of time with the first place that uses your findings. (3) Closely supervise other early adopters to prevent mistakes which could cause the method or technology to fail. (4) Do not allow your technology to get tied up in patent disputes.

(C) 2003 Elsevier Science B.V. All rights reserved.
\end{abstract}

Keywords: Cattle; Pigs; Slaughter; Restraint; Handling; Welfare; Technology transfer

\footnotetext{
ts D.G.M. Wood-Gush Memorial Lecture, 35th International Congress of the ISAE Davis, CA, 2001.

"Tel.: +1-970-491-0234; fax: +1-970-491-5326.

E-mail address: cmiller@ceres.agsci.colostate.edu (T. Grandin).
} 


\section{Introduction}

There is a large amount of behavioral knowledge that has not been successfully transferred to the industry. Based on my experience in the United States, many people in the pork industry do not know about the extensive research that has been done on pig behavior. Some upper level managers of large corporate pig farms are not even aware that behavior is a field of research. There is a need to do a much better job of transferring research results into industry language and practices. This paper is divided into five sections: (1) How to get people to recognize the importance of behavioral knowledge and behaviorally-based management methods, and addressing the problem that some people in the industry do not want to discover that a common agricultural practice may be stressful or painful; (2) How to encourage the successful transfer of behaviorally-based technology to the industry; (3) How to avoid failure to transfer a good piece of equipment that is based on behavioral research to the industry; (4) How to maintain and motivate excellent stockmanship and animal handling; and (5) Conclusions.

\section{Recognizing the importance of behavioral management of animals}

Years ago W.D. Hoard, the founder of Hoard's Dairyman magazine recognized the importance of good stockmanship (Rankin, 1925). Since that time, many research studies have shown that good stockmanship improves animal productivity. Seabrook's (1972) work was some of the first to show the importance of good stockmanship on productivity of dairy farms. Albright (1978) reported that cows with small flight zones that allowed people to approach them were more productive and gave more milk. Hemsworth et al. (1981) reported that farms on which sows were more willing to approach a person had greater productivity and more piglets per sow per year. In another study, milk production was lowered when a handler who had previously treated cows in a severely aversive manner was present (Rushen et al., 1999). A recent study by Munksgaard et al. (2001) showed that the presence of an additional person who had treated cows in a mildly aversive manner did not affect milk yield. In this study, the cows were milked by the regular dairy farm staff. In most studies linking stockmanship with productivity, the most significant variable is the behavior of the regular milker or caretaker. It is likely, that if the cows in Munksgaard et al.'s (2001) study had associated the regular milker with aversive acts, there would have been a more detrimental effect on milk production than that found when the cows associated a bystander with something aversive.

Further research by Voisinet et al. (1997) and Fell et al. (1999) has shown that cattle that became agitated during handling in a squeeze chute had lower weight gains and more sickness. In their book, Hemsworth and Coleman (1998) review a number of studies indicating that people who have a good attitude towards animals have more productive animals.

Even though numerous studies conducted on almost every livestock species show the advantages of good stockmanship, adoption of good stockmanship principles has been slower than adoption of behaviorally-based facility designs. During the last 20 years, I have written many articles on behaviorally-based cattle-handling principles (Grandin, 1980, 
1987, 1996, 1998a). However, many people still handle beef cattle roughly and have poor stockmanship skills. On some large dairies, the level of stockmanship is still poor. Why is all this research on good stockmanship ignored by a large portion of the industry? I have observed that people will adopt new handling equipment-based on behavioral principles much more quickly than they will adopt behavioral principles that they have to learn and practice. In my business, I sell twice as many books on how to build corrals and races-based on behavioral principles than I sell videotapes that can be used to train stockpersons, even though the costs of the books and tapes are nearly the same. Many people want the "thing" rather than learning better management practices. They think buying the technology is all that they need to do.

Even when a behavioral method has been documented to make money, people have been slow to adopt it. In one slaughter plant I documented a US\$ 500 to US\$ 1000 savings per day by training people to handle cattle quietly. After I left, they quickly reverted back to their old rough ways.

Why are some people so reluctant to learn and adopt behavioral principles of quiet animal handling? I have observed many managers that want a quick, easy fix and learning good stockmanship skills requires time and effort. My own visits to several hundred farms and meat plants indicate that the operations that maintain good stockmanship have either an owner or a high level manager who insists upon it. I would also like to speculate that one reason may be that to be a good stockman one must recognize that the animal is a conscious being that has feelings. It is not a machine or just an economic entity. Hemsworth and Coleman (1998) have done extensive work on the attitude of the stockperson and its effect on productivity in pigs and dairy cattle. Hemsworth et al. (2002) found that stockpersons who have a positive attitude towards their cows have higher milk yields and fewer negative tactile interactions with cows such as hitting. Hemsworth et al. (2000) further reported that stockperson training improved the stockperson's attitude towards the cows and subsequently improved productivity. The materials that these researchers have used to train stockpersons teach a lot of basic information about cow behavior. It is likely that learning more about how cows behave would make a person less likely to view an animal as a machine. From my own work on teaching people basic principles of beef handling, I have found that many people are surprised to learn that "dumb" cattle have so many different behaviors.

I have also observed that some management people in the livestock industry do not want to find out that a commonly used agricultural practice is either stressful or painful to an animal. For example, several studies have clearly shown that castrating piglets without an anesthetic is stressful and painful (McGlone and Hellman, 1988; McGlone et al., 1993; White et al., 1995). Some industry people have criticized researchers for doing studies on the use of anesthetics and analgesics for dehorning and castration because it would increase costs. My discussions with different researchers suggest that funding for research in areas where the results may force the change of a common agricultural practice is often difficult to get.

I have also observed that there is a certain percentage of physiologists and veterinarians who do not recognize the importance of behavior in assessing the pain or stress associated with certain procedures. The animal may be violently struggling and vocalizing but the physiologist will say, "It is not distressed because its physiological measures are low." 
Would the physiologist say the same thing if a person was screaming in pain when a dentist drill hit a nerve? To address this issue, more research is needed on brain neurotransmitter systems so that behavior can be correlated with activity in specific brain systems, which are known to be associated with distress in humans.

While discussing distress in animals, it is important to separate the variables of pain and fear. Brain research has shown that the mechanisms and circuits that process pain and those that process fear are different. Fear is processed in more primitive lower brain areas than pain. Fear conditioning takes place in a subcortical circuit through the amygdala (LeDoux, 1996; Rogan and LeDoux, 1996). It can take place when the entire cortex is removed (Medina et al., 2002). The role of the frontal cortex is different for fear and pain. Activation of the frontal cortex is required to extinguish a conditioned fear response (Rogan and LeDoux, 1996). However, just the opposite happens for pain. When the cortex is removed, a rat can no longer suffer from pain (Woolf, 1983). Brain scan studies in humans show that activation of the frontal cortex makes pain worse and reduces fear (Fischer et al., 1998; Apkarian et al., 2001; Fulbright et al., 2001). Much more research is needed to differentiate animal responses to pain or fear. Both of these variables either singly or combined would create distress.

Another component of the broad term distress would be physical stresses such as fatigue or heat stress during a long truck ride. All of these variables would interact together to cause distress. For example, a tame animal that is accustomed to handling would have less fear during loading and unloading from a truck than an animal that is not accustomed to being handled (Grandin, 1997a). Antelopes that had been trained to voluntarily enter a crate for blood sampling had almost baseline cortisol levels and significantly lower glucose levels compared to animals immobilized with a dart (Phillips et al., 1998).

\section{How to encourage successful transfer of behavioral-based technology to the industry}

Research results on animal handling, transport and stunning methods have been successfully transferred to the livestock industry in some areas. Hoenderken's (1982) and Gregory and Wotton's (1984) work on the electrical parameters for stunning pigs and sheep are used worldwide. Transportation guidelines for stocking density in trucks are also widely used (Warris, 1998; Knowles, 1998; Tarrant and Grandin, 2000). My own work on the design of cattle and pig handling systems for ranches, feedlots and slaughter plants is used world-wide (Grandin, 1980, 1982, 1992, 1997b, 1998a, 2000a).

One of the reasons I was able to successfully transfer cattle-handling facility designs to the industry is that I wrote over a hundred articles in the livestock industry press on behaviorally-based cattle-handling. I also posted the designs on my website http://www.grandin.com and gave talks at cattle producer meetings. I gave away the designs and made a living by charging for custom designs and consulting. People are often too reluctant to give information away. I discovered that when I gave out a lot of information I got more consulting jobs than I could handle. However, it may be advantageous to keep quiet about new ideas when they are in the early development stage. 


\subsection{Case history of a successful behaviorally-based technology transfer}

The center track or double rail conveyor restrainer for handling cattle in slaughter plants is now being successfully used in 26 plants in the United States, Canada and Australia. Half of the cattle in the US and Canada are handled in this system when they go to slaughter. The case history of this system is a good example of a technology that started in the research laboratory and was adopted by many of the world's largest beef plants.

The Council for Livestock Protection funded the original project during the early 1970s. The council was a consortium of US animal welfare groups, which included the Humane Society of the United States and the American Society of Prevention of Cruelty to Animals. In the early 1970 s, the council gave a grant of US $\$ 60,000$ to researchers at the University of Connecticut to develop a method to replace cruel shackling and hoisting of conscious calves and sheep by one rear leg, which was commonly used prior to kosher slaughter.

The Connecticut researchers began with a complete search of all patents and literature to determine the "state of the art" prior to inventing new designs. A complete review of the literature is important to prevent "reinventing the wheel." The researchers invented the idea of having the calf or lamb straddle a moving conveyor and they were able to demonstrate that this method of restraint was low stress (Westervelt et al., 1976; Giger et al., 1977). The Council patented the system so that no one else could patent it and block transmission of the invention to the industry.

The Connecticut researchers initially developed a laboratory prototype but many more components had to be invented to make a commercially usable system. In 1985, the Council for Livestock Protection gave another US\$ 100,000 grant to design and build a system for a commercial veal slaughter plant. I was hired to do this job. I invented a new entrance design to facilitate calf entry onto the conveyor and I added adjustable sides for different sized animals (Grandin, 1988). To make my design available, I published the drawings and placed them in the public domain. This prevented people outside the US from patenting it. The system was then installed in two other veal plants.

I knew that this system would also work really well for large cattle, but plant managers were reluctant to try the new design until I obtained a second grant from an independent animal welfare advocate in Florida. This made it possible to give a restrainer to a plant that was willing to pay for building remodeling costs. Since larger cattle are wilder and more difficult to handle than tame milk formula fed veal calves, I had to modify the system even further to keep the large cattle calm. I added a solid roof (hold down) over the head of the cattle to block their vision and to prevent them from seeing an escape route until they were fully restrained (Grandin, 1991). This roof did not press down and physically hold the animal down (Fig. 1), but simply blocked the animal's view of an escape route until the animal's back feet were off the entrance ramp and he was completely settled down on the conveyor restrainer and supported by his brisket and belly. A solid false floor was also added to prevent animals from seeing the "visual cliff" effect as they entered the restrainer (Fig. 2). The conveyor was mounted $2 \mathrm{~m}$ off the floor and animals would often refuse to enter if they could see the steep drop off (Grandin, 2001). The false floor provided the optical illusion of a solid floor to walk on. As the animal entered, it was centered high on the moving conveyor and its feet were $20 \mathrm{~cm}$ above the false floor. These extra pieces of metal that controlled what the cattle could see were essential. Cattle remained calm and entered 


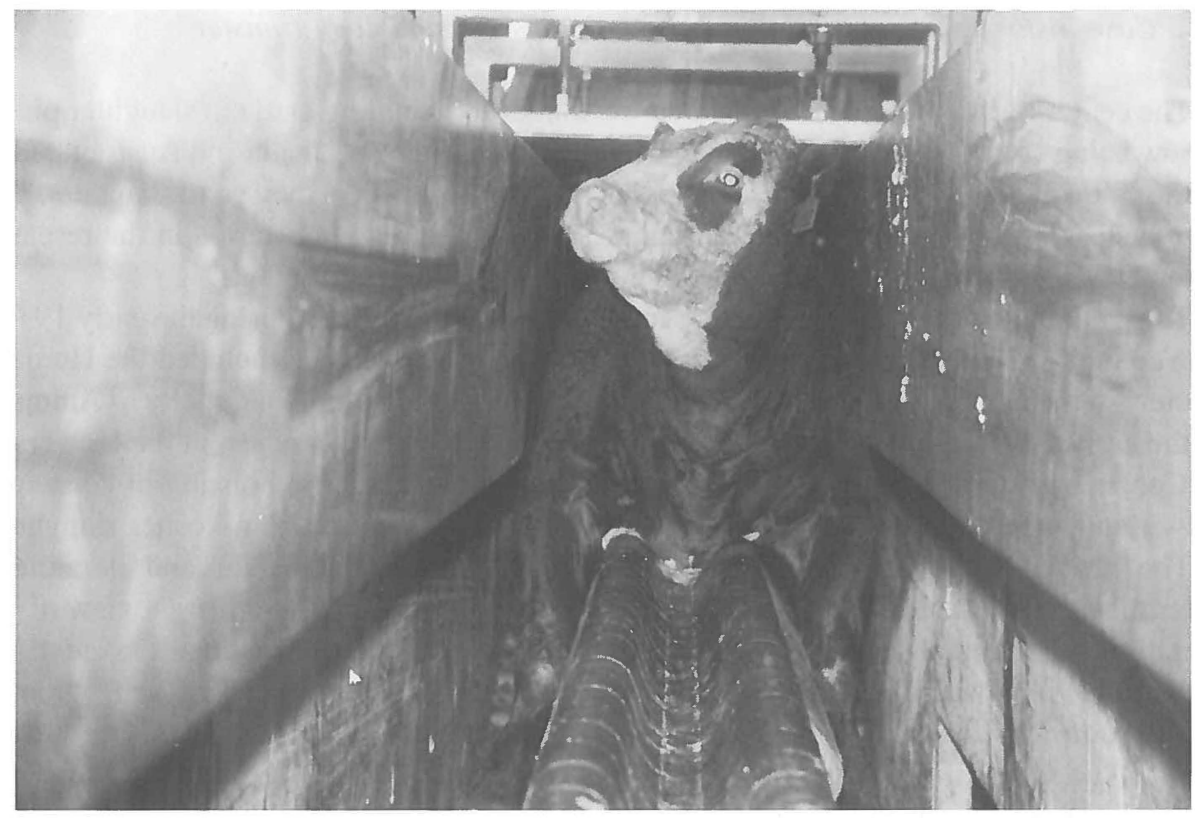

Fig. 1. A steer sits quietly on the center track conveyor which is shaped to fit its brisket. The solid roof over the steer's head must be long enough to block his vision until his back feet are off the entrance ramp. The maximum width of the conveyor is $30 \mathrm{~cm}$ (reprinted from Grandin, 2000a).

the restrainer easily when the vision blocking panels were installed. Prior to installation of the false floor and solid roof the cattle often became extremely agitated. Details of design are important.

Transferring this technology out of the first successful beef plant to the rest of the industry was very time consuming. I visited the next seven plants that installed the

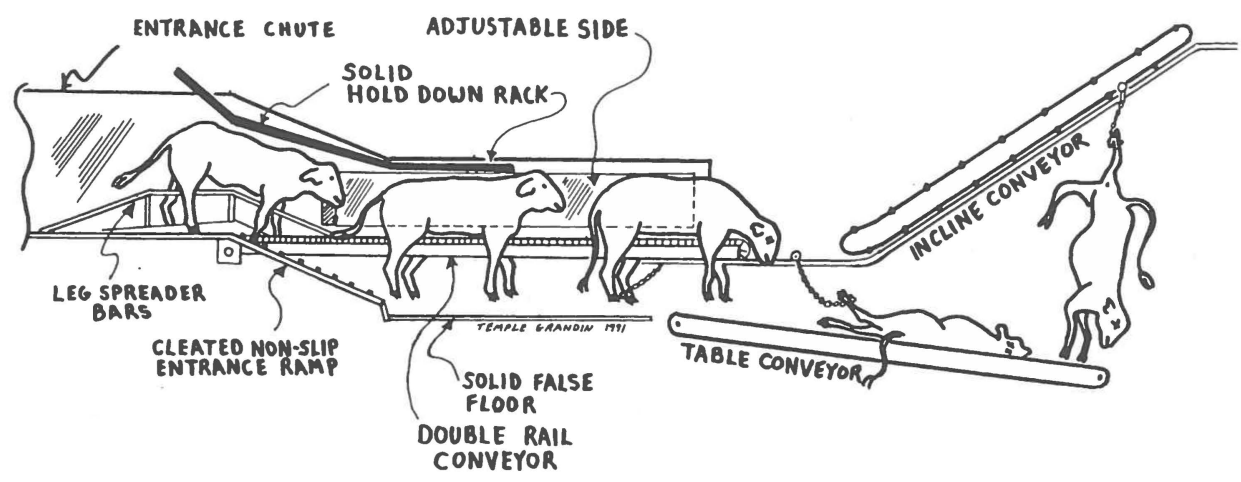

Fig. 2. Diagram of the center track (double rail) conveyor restrainer system. A false floor below the animal's feet prevents incoming cattle from seeing a $2 \mathrm{~m}$ high drop off under the conveyor. A non-slip entrance ramp is essential. Cattle back out if they slip (reprinted from Grandin, 2000a). 
equipment to make sure it was installed correctly. Improper installation and bad modifications made by steel welding companies caused big problems. I had to be there at startup to correct these problems. Equipment installers often failed to install the false floor or shortened the overhead roof that blocked the cattle's vision. They did not understand a purely behavioral reason for having extra metal that would need to be cleaned. At the second plant, the welders shortened the solid roof, and the cattle often struggled. I demonstrated the need for a longer roof by laying a $70 \mathrm{~cm} \times 60 \mathrm{~cm}$ wide piece of cardboard across the system to lengthen it. That piece of cardboard instantly made $450 \mathrm{~kg}$ cattle with large flight zones become calm. That demonstration of the power of behavioral principles in the design convinced the welders to replace the cardboard with additional metal sheets. Three different equipment construction companies did not build the false floor and I had to go to the plants and put it back on, because the cattle balked and refused to enter the restrainer and ride on the moving conveyor. The false floor was clearly marked on all the drawings provided to the equipment companies. Transfer of the restrainer technology to the industry could have failed if I had not been there to correct mistakes made by the early adopters.

One month before this lecture, I visited a recent restrainer installation. They had built the false floor and the overhead roof correctly, but they had omitted two belly rails that keep the cattle centered as they enter the restrainer. This is a third important behavioral component of the design. To induce the large cattle to straddle the leg spreader bar, the entrance race must be made narrower at the animal's belly height; and be wider at the floor to provide the animal with adequate space for walking (Fig. 3). When the belly rail was missing, the cattle had a tendency to walk on one side of the leg spreader bar instead of straddling it.

Working on the center track conveyor restrainer system convinced me of the power of using behavior principles for handling large cattle that were not accustomed to close contact with people. Some of the range cows successfully handled in this system were wild

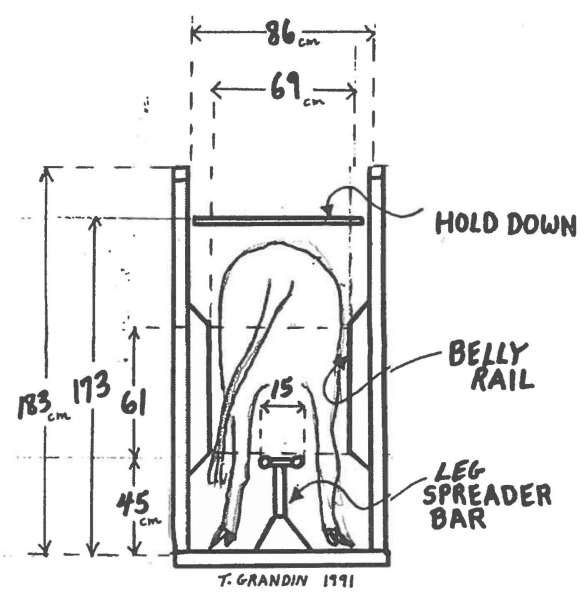

Fig. 3. Belly rail that keeps the animal centered as it enters the center track conveyor. 
animals. The behavioral principles necessary for keeping the animals calm in this system are:

1. Block vision of an escape route until the animal is completely restrained.

2. Do not allow incoming animals to see the visual cliff effect.

3. Equipment must move with steady motion and have no jerky motion.

4. Slipping frightens animals and the system must have a non-slip entrance ramp.

5. Optimal pressure: The adjustable sides had to hold the animal snugly enough so it felt held but not so tightly as to cause pain or discomfort.

\subsection{How to successfully transfer knowledge}

Scientists need to spend more time communicating with the public and the livestock community about the importance of their work. Doing this often requires writing many similar articles for the livestock magazines. The research must also be published in the scientific literature to provide a permanent, accessible record of the knowledge. This prevents knowledge from being lost.

Scientists also need to learn how to write without jargon. Scientific writing needs to be precise, but sometimes a simple word is just as precise. One of the things that I have learned during my career of successfully transferring behavioral knowledge, is that transfer of the knowledge is more difficult and time consuming than doing the research that generates the knowledge. It is also extremely important that the first places that attempt to adopt the technology are successful. If the early adoptees of a technology fail, the word will get out and convincing more people to adopt the technology will be more difficult. To ensure that the early adopters are successful requires a great deal of time working to ensure that the method or equipment is used correctly.

\section{How to avoid failure to transfer research results to industry}

Researchers and producers have developed a number of behaviorally-based designs for equipment that have not been adopted by the industry. These include several excellent farrowing stalls for sows that allow the sow to turn around (Fraser et al., 1988; Lou and Hurnik, 1994). These stalls could be cost competitive and they could be easily adopted. Another excellent behaviorally-based design that has not been adopted by the largest US pork companies is a feeder design based on the ergonomics of pig eating behavior that prevents the pig from wasting feed. A kinematic analysis of the sow's eating movements was used to identify the spatial requirements for optimal feeder design and reduced feed wastage (Taylor et al., 1987, 1989; Taylor, 1990). Many commonly used feeder designs have feed wastage of up to 20\% (Taylor et al., 1986; Taylor and Curtis, 1989a,b).

Why are these excellent and cost effective behaviorally-based designs not being widely used? Baxter (1995) states that one difficulty is that there is a fundamental difference between the approach of scientists and designers to a problem. Scientists seek knowledge and designers seek practical solutions. My own observations have shown that scientists can 
often successfully develop a project through the prototype stage, and they have difficulty getting beyond this stage.

Maybe these designs did not receive enough promotion, or some of the final development work was not completed, or some of the early adopters tried to modify the design and this resulted in problems. On one farm in the US, I know that changes in some of the dimensions caused a turn-around farrowing stall to perform more poorly than a conventional farrowing crate. Details of design are important and modifications made by people who did not know what they were doing can block the transfer of promising technologies. Modification of dimensions and installation mistakes can cause systems installed by early adopters to fail.

Even today I have to constantly check up on clients to make sure they build my cattle systems correctly. In June 2001, I checked up on a feedlot that was building a new curved race system. A draftsman had made a drawing mistake that would have ruined the system. Successful transfer of technology requires constant checking of what people are doing in the field.

Some technologies do not get adopted due to patent fights when one company buys up the patent rights to block adoption of a technology. Another business entity that has impeded adoption of some improved designs is building contractors. Building contractors design things for ease of construction. For example, ventilation in many animal buildings in the US has taken some steps backwards. They are designed for ease of construction and to sell fans instead of proper ventilation. For example, a naturally ventilated building with a pitched roof and a wide ridge vent will stay cooler in the summer than a building with a flatter roof and a small ridge vent. Contractors prefer to build the flatter roof and a small ridge vent because it is easier to build and is more profitable for them. To compensate for the poorer air movement they have to install fans. Contractors will often design things to benefit contractors instead of benefiting the animals. I could provide countless other examples. The solution is for the owner to insist that the contractor build from designs that the owner supplies. My best jobs were built by owners who insisted that the contractor not deviate from my specifications.

\section{How to maintain excellent stockmanship and animal handling}

As stated previously, people are often more willing to purchase new technology than to make a sustained commitment to better behavioral management of animals. Good stockmanship and handling is impossible if a facility is understaffed and the people are overworked. I have also observed that the method of payment affects the quality of handling. Cattle have significantly fewer bruises when the producer is held financially accountable for bruises (Grandin, 1981). Handling animals on a "piece work" basis where speed is rewarded encourages rough handling. I have seen many cattle severely injured when operation of a squeeze chute for vaccinating cattle is based solely on the numbers of cattle vaccinated per hour.

I have trained many people to handle cattle and pigs in a careful, quiet manner. For a few weeks following training, the handling practices would be good but in many cases the people reverted back to rough practices such as excessive electric prod (goad) use. I call 
this " bad becoming normal.". I have observed that people often lapse back into old bad habits and they do not even realize it. One of the reasons that this occurs is because the handlers have no standard to compare their performance against. To combat this problem, I developed a simple scoring system for animal handling at the slaughter plant (Grandin 1998b,c, 2001).

The scoring system enables management to quantify variables such as the percentage of animals shocked with an electric prod (goad), the number of animals that fall down, the percentage of cattle that vocalize during handling and the percentage of animals stunned correctly. These variables were chosen after I collected data on over 1000 cattle at slaughter plants throughout the US (Grandin, 1998b). Cattle vocalizations during movement through the chutes and during stunning are highly correlated with aversive events. Out of 1125 cattle, $98 \%$ of the vocalizations during active handling were associated with an aversive event such as an electric goad, missed stuns, slipping and falling or excessive pressure from a restraint device (Grandin, 1998c). A further study of over 5000 cattle in 40 commercial slaughter plants indicated that cattle vocalizations were associated with equipment problems (Grandin, 2001). Vocalizations during handling or during surgical procedures are highly correlated with physiological measures of stress (Dunn, 1990; Warriss et al., 1994; White et al., 1995). People manage the things that they measure. Measurement also provides a benchmark that enables people to see if their performance has improved or become worse.

Other potential methods for objectively scoring cattle handling on farms and ranches are a police radar speed camera or constructing a squeeze chute with sensors to monitor how hard an animal struggles (Burrow and Dillon, 1997; Schwartzkoph-Genswein et al., 1998). Burrow and Dillon (1997) found that cattle that ran more quickly out of a squeeze chute in which they were restrained for vaccination had lower weight gains. Animals that have been shocked repeatedly will run faster out of a squeeze chute and are more likely to struggle. Exit speed from the squeeze chute is already being used on farm audits. To simplify the audit, each bovine is scored as exiting at either a walk, trot or canter.

Animal welfare legislation and requirements specified by large customers such as supermarkets and restaurants serve as powerful motivators to use behavioral methods. In Europe, legislation has prompted the use of research results on welfare-friendly animal housing. In the United States, welfare requirements of the McDonald's Corporation and Wendy's International have greatly improved handling and stunning of cattle and pigs at slaughter plants (Grandin, 2000b). These restaurant companies are using the scoring system I developed for monitoring animal welfare in slaughter plants (Grandin, 1998b). When a restaurant auditor visits a plant, 100 cattle or pigs are scored. For cattle, the minimum passing scores are $95 \%$ of the cattle stunned with one shot and $100 \%$ rendered insensible on the bleed rail. Seventy-five percent of the cattle must be moved through the entire system without an electric goad and only $3 \%$ can vocalize. During the year 1999, a total of 48 plants were audited. Three percent or less of the cattle vocalized in $67 \%$ of the plants. Plants that repeatedly failed audits have been suspended for several months or removed from the approved supplier list. This provides a strong economic incentive to handle animals carefully. In 1996, only $30 \%$ of the plants stunned $95 \%$ or more of the cattle with one shot, and after McDonald's started these audits, $90 \%$ of the plants passed (Grandin, 1998b, 2000b). For the last 3 years this level of performance has been maintained 
through the use of yearly audits. Implementing the scoring system required many days of work. I visited over 30 beef and pork slaughter plants to teach restaurant auditors how to use the scoring system. Audits by McDonald's and Wendy's have greatly improved animal handling and stunning in US slaughter plants (Grandin, 2000b). To achieve compliance, most plants have implemented employee training and their quality assurance department conducts weekly audits using the same scoring system.

Plant managers had to make sure their employees used behavior principles in order to reduce or eliminate the use of electric prods so that they were in compliance with the welfare guidlines of their customers (i.e. Grandin, 1980, 1982, 1992. Making several simple changes in the design of the handling area such as lighting or plant ventilation made it possible to reduce or eliminate electric prod usage (Grandin, 1996, 2001). Some of the changes that improved animal movement and made it possible to reduce electric prod use were, installing solid sides on races, lighting a dark restrainer conveyor entrance, moving lamps to eliminate reflections on a wet floor, eliminating air drafts that blew in the faces of approaching animals and filling the crowd pen that leads to the single file race only half full instead of stuffing it full. With the exception of two plants, all of the 46 plants were able to comply with the standards without making large capital investments. The purchase of lamps, inexpensive non-slip floor gratings or shields to block animal vision were usually the only things they had to buy.

Another good motivator for good stockmanship is financial incentive resulting from improvements in animal productivity or from a reduction in bruises or broken bones. I have been shown internal company figures that indicate that in the poultry industry, paying catchers an incentive for reducing wing breakage resulted in a reduction in broken wings of over $100 \%$. Poultry companies in both the US and England have implemented incentive pay based on reducing broken wings and dead birds. At one company, broken wings were reduced from 3 to $4-1 \%$ on a per bird basis. Similar economic incentives could be applied on farms. A farrowing manager will work extra hard if he/she receives extra money for weaning more piglets. Milkers could be paid incentives for increased milk production.

\section{Conclusions}

Scientists need to take more initiative to get their research results adopted by the industry. From my experience, the necessary steps for successful transfer of behavioral research results to the industry are:

1. Communicate your research results by speaking to producer groups, writing in producer magazines and making websites. Results should be published in refereed scientific journals because these papers are easier to access in libraries.

2. Find a place (farm or plant) that will try your research findings and be prepared to spend a lot of time there. This place must have cooperative management. The manager of the place must believe in what you are attempting to accomplish.

3. You must supervise installation and correct mistakes made by the early adopters of your methods or technology. 
4. Do not allow your research findings to get tied up in a patent dispute because this often blocks adoption of your research findings. This is especially important for behavioral research. Make your money with consulting fees to help people to use your research.

\section{References}

Albright, J.L., 1978. The behavior and management of high yielding dairy cows. In: Proceedings of the British Oil and Cake Mills (BOCM), Silcock Conference, Silcock, London, UK, p. 31.

Apkarian, A.V., Thomas, P.S., Krauss, B.R., Szeverenyi, N.M., 2001. Prefrontal cortical hyperactivity in patients with sympathetically mediated chronic pain. Neurosci. Lett. 311, 193-197.

Baxter, M., 1995. There is more to design than behavior. In: Proceedings of the Animal Behavior and Design of Livestock and Poultry Systems. Northeast Regional Agricultural Engineering Service, Cooperative Extension, Cornell University, Ithaca, NY, pp. 73-82.

Burrow, H.M., Dillon, R.D., 1997. Relationship between temperament and growth in a feedlot and commercial carcass traits in Bos indicus crossbreds. Aust. J. Exp. Agric. 37, 407-411.

Dunn, C.S., 1990. Stress reactions of cattle undergoing ritual slaughter using two methods of restraint. Vet. Rec. $126,522-525$.

Fell, L.R., Colditz, I.G., Walker, K.H., Watson, D.L., 1999. Associations between temperament, performance and immune function in cattle entering a commercial feedlot. Aust. J. Exp. Agric. 39, 795-802.

Fischer, H., Andersson, J.L., Furmark, T., Fredrikson, M., 1998. Brain correlates of an unexpected panic attack: a human positron emission tomographic study. J. Neurosci. Lett. 251, 137-140.

Fraser, D., Phillips, P.A., Thompson, B.K., 1988. Initial test of a farrowing crate with inward sloping sides. Livestock Prod. Sci. 20, 249-256.

Fulbright, R.K., Troche, C.J., Skudlarski, P., Gore, J.C., Wexler, B.E., 2001. Functional MRI imaging of regional brain activation associated with the effective experience of pain. Am. J. Roetgenol. 177, 1205-1210.

Giger, W., Prince, R.P., Westervelt, R.G., Kinsman, D.M., 1977. Equipment for low stress animal slaughter. Trans. Am. Soc. Agric. Eng. 20, 571-578.

Grandin, T., 1980. Observations of cattle behavior applied to the design of cattle handling facilities. Appl. Anim. Ethol. 6, 19-31.

Grandin, T., 1981. Bruises on southwestern feedlot cattle. J. Anim. Sci. 53 (1), 213 (Abstract).

Grandin, T., 1982. Pig behavior studies applied to slaughter plant design. Appl. Anim. Ethol. 9, 141-151.

Grandin, T., 1987. Animal handling. Vet. Clin. North Am. Food Anim. Pract. 3, 323-328.

Grandin, T., 1988. Double rail restrainer conveyor for livestock handling. J. Agric. Eng. Res. 41, 327-338.

Grandin, T., 1991. Double rail restrainer for handling beef cattle. Paper No. 91-5004. American Society of Agricultural Engineers, St. Joseph, MI.

Grandin, T., 1992. Observations of cattle restraint devices for stunning and slaughtering. Anim. Welfare 1, 85-91.

Grandin, T., 1996. Factors that impede animal movement at slaughter plants. J. Am. Vet. Med. Assoc. 209, 757-759.

Grandin, T., 1997a. Assessment of stress during handling and transport. J. Anim. Sci. 75, 249-257.

Grandin, T., 1997b. The design and construction of facilities for handling cattle. Livestock Prod. Sci. 49, 119.

Grandin, T., 1998a. Handling methods and facilities to reduce stress in cattle. Vet. Clin. North Am. Food Anim. Pract. 14, 325-341.

Grandin, T., 1998b. Objective scoring for animal handling and stunning practices in slaughter plants. J. Am. Vet. Med. Assoc. 212, 36-93.

Grandin, T., 1998c. The feasibility of using vocalization scoring as an indicator of poor welfare during slaughter. Appl. Anim. Behav. Sci. 56, 121-128.

Grandin, T., 2000a. Livestock Handling and Transport, second ed. CAB International, Wallingford, Oxon, UK.

Grandin, T., 2000b. Effect of animal welfare audit of slaughter plants by a major fast food company in cattle handling and stunning practices. J. Am. Vet. Med. Assoc. 216, 848-851.

Grandin, T., 2001. Cattle vocalizations are associated with handling and equipment problems at beef slaughter plants. Appl. Anim. Behav. Sci. 71, 191-201.

Gregory, N.G., Wotton, S.B., 1984. Sheep slaughtering procedures. III. Head to back electrical stunning. Br. Vet. J. $140,570-575$. 
Hemsworth, P.H., Coleman, G.J., 1998. Human Livestock Interactions: The Stock Person and the Productivity and Welfare of Intensely Farmed Animals. CAB International, Wallingford, Oxon, UK.

Hemsworth, P.H., Barnett, J.L., Hensen, C., 1981. The influence of handling by humans on the behavior, growth and carticostenoids in the juvenile female pig. Horm. Behav. 15, 396-403.

Hemsworth, P.H., Coleman, G.J., Barnett, J.L., Borg, S., 2000. Relationships between human animal interactions and productivity of commercial dairy cows. J. Anim. Sci. 78, 2821-2831.

Hemsworth, P.H., Coleman, G.L., Barnett, J.L., Borg, S., Dowling, S., 2002. The effects of cognitive behavioral intervention on the attitude and behavior of stockpersons and the behavior and productivity of commercial dairy cows. J. Anim. Sci. 80, 68-78.

Hoenderken, R., 1982. Electrical and carbon dioxide stunning of pigs for slaughter. In: Eikelenboom, G. (Ed.), Stunning Animals for Slaughter. Martinus-Nijhoff, Dorderecht, pp. 59-63.

Knowles, T.G., 1998. A review of road transport of sheep. Vet. Rec. 144, 197-201.

LeDoux, J.E., 1996. The Emotional Brain. Simon \& Schuster, New York.

Lou, Z., Hurnik, J.F., 1994. An ellipsoid furrowing crate: its ergonomical design and effects on pig productivity. J. Anim. Sci. 72, 2610-2616.

McGlone, J.J., Hellman, J.M., 1988. Local and general anesthetic effects on behavior and performance of 2 and 7 week old castrated and non-castrated piglets. J. Anim. Sci. 66, 3049-3058.

McGlone, J.J., Nicholson, R.I., Hellman, J.M., Herzog, D.N., 1993. The development of pain associated with castration and attempts to prevent castration induced behavioral changes. J. Anim. Sci. 71, 1441-1446.

Medina, J.F., Repa, J.C., Mauk, M.D., LeDoux, J.E., 2002. Parallels between cerebellar and amygdala dependent conditioning. Nat. Rev. Neurosci. 3, 122-131.

Munksgaard, L., dePasille, A.M., Rushen, J., Harkin, M.S., Kristensen, A.M., 2001. Dairy cows fear of people. Social learning, milk yield and behavior at milking. Appl. Anim. Behav. Sci. 73, 15-26.

Phillips, M., Grandin, T., Graffam, W., Irlbeck, N.A., Cambre, R.C., 1998. Crate conditioning of bongo (Tragelaphus eurycerus) for veterinary and husbandry procedures at Denver Zoological Garden. Zoo Biol. $17,25-32$.

Rankin, G.W., 1925. The Life of William Dempster Hoard. W.D. Hoard and Sons Press, Fort Atkinson, WI.

Rogan, M.T., LeDoux, J.E., 1996. Emotion: systems, cells, synaptic plasticity. Cell 85, 469-475.

Rushen, J., dePasille, A.M.B., Munksgaard, L., 1999. Fear of people by cows and effects on milk yield behavior and heart rate at milking. J. Dairy Sci. 82, 720-727.

Schwartzkoph-Genswein, K.S., Stookey, J.M., Crowe, J.M., Genswein, R.M., 1998. Comparison of image analysis, exertion force and behavior measurements for assessment of beef cattle response to hot iron and freeze branding. J. Anim. Sci. 76, 972-979.

Seabrook, M.F., 1972. A study to determine the herdsman's personality in milk yield. J. Agric. Labor Sci. 1, 45-59.

Tarrant, V., Grandin, T., 2000. Cattle transport. In: Grandin, T. (Ed.), Livestock Handling and Transport. CAB International, Wallingford, Oxon, UK, pp. 151-173.

Taylor, I.A., 1990. Design of the sow feeder: a systems approach. University Microfilms International, Ann Arbor, MI (Ph.D. Dissertation, University of Illinois, Urbana-Champaign, IL).

Taylor, I.A., Curtis, S.E., 1989a. Grower Feeders: 11 Designs Reviewed. National Hog Farmer. December 1989.

Taylor, I.A., Curtis, S.E., 1989b. Nursery Feeders: Researchers Find Feed Waste ranges From 2\% to $11 \%$ in Tests. National Hog Farmer. May 1989.

Taylor, I.A., Curtis, S.E., Feinmehl, R.I., 1986. Amounts of feed mated gilts spilled and left with six feeder models. J. Anim. Sci. 63 (1), 96 (Abstract).

Taylor, I.A., Groppel, J.L., Curtis, S.E., 1987. Kinematic analysis of eating movements in sows. J. Anim. Sci. 65 (1), 233 (Abstract).

Taylor, I.A., Curtis, S.E., Taylor, K., Russell, K., 1989. Feed wastage from eleven commercial models of nursery feeder. J. Anim. Sci. 67 (Suppl. 1), 94 (Abstract).

Voisinet, B.D., Grandin, T., Tatum, J.D., O’Connor, S.F., Struthers, J.J., 1997. Feedlot cattle with calm temperaments have higher average daily gains than cattle with excitable temperaments. J. Anim. Sci. 75, 892-896.

Warris, P.D., 1998. Choosing appropriate space allowances for slaughter pigs transported by road: a review. Vet. Rec. 142, 449-454.

Warriss, P.D., Brown, S.N., Adams, S.J.M., 1994. Relationship between subjective and objective assessment of stress at slaughter and meat quality of pigs. Meat Sci. 38, 329-340. 
Westervelt, R.G., Kinsman, D., Prince, R.P., Giger, W., 1976. Physiological stress measurement during slaughter of calves and lambs. J. Anim. Sci. 42, 831-834.

White, R.C., DeShazer, J.A., Tressler, C.J., Borches, G.M., Davey, S., Waninge, A., Parkhust, A.M., Milanuk, M.J., Clems, E.I., 1995. Vocalizations and physiological response of pigs during castration with and without anesthetic. J. Anim. Sci. 73, 381-386.

Woolf, C.J., 1983. Evidence for central component of post-injury pain hypersensitivity. Nature 306, 686 . 